\title{
Trichosanthin inhibits DNA methyltransferase and restores methylation-silenced gene expression in human cervical cancer cells
}

\author{
YILING HUANG ${ }^{1,2}$, HUAMEI SONG ${ }^{2}$, HUOJUN HU ${ }^{3}$, LEI CUI ${ }^{1,2}$, CHENGCHENG YOU ${ }^{2}$ and LIMING HUANG ${ }^{1}$ \\ ${ }^{1}$ Department of Oncology, Zhongnan Hospital, Wuhan University, Wuhan 430070; ${ }^{2}$ Department of Pathology, \\ China Three Gorges University Medical College, Yichang 443002; ${ }^{3}$ Department of Neurosurgery, \\ The First Clinical Medical College of China Three Gorges University, Yichang 443000, P.R. China
}

Received March 9, 2012; Accepted July 9, 2012

DOI: $10.3892 / \mathrm{mmr} .2012 .994$

\begin{abstract}
Epigenetic silencing of tumor suppressor genes is a well-established oncogenic process and the reactivation of tumor suppressor genes that have been silenced by promoter methylation is an attractive molecular target for cancer therapy. In this study, we investigated the demethylation activity of trichosanthin (TCS, the main bioactive component isolated from a Chinese medicinal herb) and its possible mechanism of action in cervical cancer cell lines. HeLa human cervical adenocarcinoma and CaSki human cervical squamous carcinoma cells were treated with various concentrations $(0,20,40$ and $80 \mu \mathrm{g} / \mathrm{ml}$ ) of TCS for $48 \mathrm{~h}$ and the mRNA and protein expression levels of the tumor suppressor genes adenomatous polyposis coli (APC) and tumor suppressor in lung cancer 1 (TSLC1) were detected using reverse transcription (RT)-PCR and western blotting, respectively. We analyzed the methylation status of APC and TSLC1 using methylation-specific PCR (MSP). The expression levels and enzyme activity of DNA methyltransferase 1 (DNMT1) were also examined. The mRNA and protein expression levels of APC and TSLC1 were increased following treatment with various concentrations $(0$, 20,40 and $80 \mu \mathrm{g} / \mathrm{ml}$ ) of TCS for $48 \mathrm{~h}$. The expression of the APC

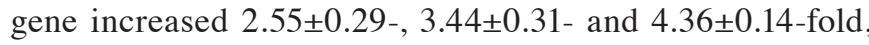
respectively. The expression of the TSLC1 gene increased 2.28 $\pm 0.15-, 4.23 \pm 0.88$ - and 6.09 \pm 0.23 -fold, respectively. MSP detection showed that TCS induced demethylation in HeLa
\end{abstract}

Correspondence to: Professor Liming Huang, Department of Oncology, Zhongnan Hospital, Wuhan University, 169 Donghu Road, Wuhan, Hubei 430070, P.R. China

E-mail: hlmyj8265@126.com

Abbreviations: TCS, trichosanthin; RIP, ribosome-inactivating protein; TSLC1, tumor suppressor in lung cancer 1; APC, adenomatous polyposis coli; MSP, methylation-specific PCR; IVD, methylated positive control; NL, unmethylated positive control

Key words: trichosanthin, cervical cancer, DNA methylation and CaSki cells and that this demethylation activity was accompanied by the decreased expression of DNMT1 and reduced DNMT1 enzyme activity. Our experimental results demonstrate for the first time that TCS is capable of restoring the expression of methylation-silenced tumor suppressor genes and is potentially useful as a demethylation agent for the clinical treatment of human cervical cancer.

\section{Introduction}

Aberrant gene promoter hypermethylation is a reversible epigenetic alteration which results in the silencing of tumor suppressor genes and plays a critical role during cervical tumorigenesis $(1,2)$. The methylation of $\mathrm{CpG}$ islands involves the transfer of a methyl group from S-adenosyl-L-methionine to the fifth carbon position of cytosine by DNA methyltransferases (DNMTs). Several DNA methyltransferases, including DNMT1, DNMT3a, DNMT3b and DNMT31, have been identified in mammals $(3,4)$. DNMT1 is responsible for most of the methylation of the human genome and for maintaining the preexisting DNA methylation patterns following replication (5). An increase in the activity or amount of DNMT1 is believed to be involved in carcinogenesis. The cancer methylome is highly disrupted, making DNA methylation an excellent target for anticancer therapies (6). During the last few decades, several demethylating agents have been evaluated in preclinical and clinical studies. 5-Aza-cytidine and 5-aza-2'-deoxycytidine are the most studied and were developed over 30 years ago as classical cytotoxic agents, but were subsequently found to be effective DNA methylation inhibitors (7). Zebularine is an oral cytidine that induces demethylation and reactivation of the silenced p16 gene (8). Certain other drugs, including procainamide and hydralazine, are also at various stages of trial (9), but the number of available DNMT inhibitor compounds with a high efficacy and low toxicity remains limited. Therefore, the development of novel effective DNMT inhibitors would be of benefit.

Trichosanthin (TCS) is a type I ribosome-inactivating protein (RIP) comprising 247 amino acids that may be extracted from the root tubers of the Chinese medical herb Trichosanthes kirilowi. The primary sequence and 
three-dimensional structure of TCS were elucidated in the early 1990s $(10,11)$. TCS has been used as an abortifacient for 1,500 years in China due to its high toxicity on trophoblasts. Over the past 20 years, TCS has been the subject of much study due to its potential antitumor activity. TCS reportedly exhibits effective cytotoxicity in a variety of tumor cell lines but has no clear cytotoxicity in normal cell lines (12). In vitro and in vivo studies revealed that TCS exerts antitumor activity through the induction of apoptosis and inhibition of cell proliferation (13-15). TCS-induced apoptosis in JAR cells (human choriocarcinoma cells) was reportedly reduced in [Y55G] and [FYY140-GSA142] TCS variants in which there were changes in the secondary structure and decreases in ribosome-inactivating activity, suggesting that apoptosis occurs as a result of ribosome inactivation (16).

In this study, we determined whether TCS is capable of inducing demethylation of the $\mathrm{CpG}$ islands of the tumor suppressor genes adenomatous polyposis coli (APC) and tumor suppressor in lung cancer 1 (TSLC1) and restoring their expression in cervical cancer cell lines. We also investigated whether this demethylation activity was accompanied by the decreased expression of DNMT1 and reduced DNMT1 enzyme activity.

\section{Materials and methods}

Cell cultures and reagents. The human cervical cancer cell lines HeLa and CaSki were obtained from the American Type Culture Collection (ATCC, Manassas, VA, USA). These cells were cultured at $37^{\circ} \mathrm{C}$ in a humidified atmosphere containing $5 \% \mathrm{CO}_{2}$ in RPMI-1640 (Invitrogen, Carlsbad, CA, USA) supplemented with $10 \%$ fetal bovine serum (FBS), $100 \mathrm{U} / \mathrm{ml}$ penicillin and $100 \mu \mathrm{g} / \mathrm{ml}$ streptomycin. TCS $(1.2 \mathrm{mg} / \mathrm{ml})$ was purchased from Shanghai Jinshan Medicine Co., Ltd. (Shanghai, China). The primers listed in Tables I and II were synthesized by Sangon Biological Engineering Technology \& Services Co., Ltd. (Shanghai, China).

RNA isolation and semi-quantitative reverse transcription $(R T)-P C R$. Total RNA was isolated using TRIzol reagent (Invitrogen). RNA purity and concentrations were determined by measuring A260/A280 absorption. cDNA was synthesized from $1 \mu \mathrm{g}$ of RNA using oligo-(dT) primers (Toyobo Co., Ltd., Osaka, Japan). Following first-strand synthesis, the reaction mixture was diluted to $100 \mu \mathrm{l}$ with water. Subsequently, $5 \mu \mathrm{l}$ of the diluted cDNA mixture was used for PCR amplification in a final 25- $\mu 1$ reaction volume. PCR amplification for APC, TSLC1 and DNMT1 was carried out using the primer sets listed in Table I (17-19). $\beta$-actin was amplified as an internal control.

Quantitative real-time PCR. Total cellular RNA was isolated and the reverse transcription step was performed as described above. Quantitative real-time PCR was carried out using the primers listed in Table I. Each reaction was set up in a final 25- $\mu 1$ reaction volume containing $10 \mathrm{pmol}$ of each primer, $5 \mu \mathrm{l}$ of the diluted cDNA mixture, $3.5 \mathrm{mmol} / 1 \mathrm{MgCl}_{2}$ and 0.5X SYBR-Green I (Generay Biotech Co., Ltd., Shanghai, China). The PCR conditions used were as: 5 min denaturation at $95^{\circ} \mathrm{C}$, followed by 40 cycles of $95^{\circ} \mathrm{C}$ for $30 \mathrm{sec}, 56^{\circ} \mathrm{C}$ for $30 \mathrm{sec}$ and $72^{\circ} \mathrm{C}$ for $30 \mathrm{sec}$. Amplification of the target gene was monitored as a function of increased SYBR Green I fluorescence. The comparative expression of the APC, TSLC1 and DNMT1 genes relative to the expression of $\beta$-actin was determined by $2^{-\Delta \Delta \mathrm{Ct}}$ and $\Delta \Delta \mathrm{Ct}$ was determined using the formula: $\Delta \Delta \mathrm{Ct}=\Delta \mathrm{Ct}_{\text {experiment }}-\Delta \mathrm{Ct}_{\text {control }}$. The melting curve and quantitative analysis of the data were performed using Option Monitor 2.02.24 software.

Bisulfite modification and methylation-specific PCR (MSP). Genomic DNA from the untreated and treated human cervical cancer cell lines was extracted using the Tissue/Cell Genomic DNA Isolation kit (Watson Biotechnologies Inc., Shanghai, China) according to the manufacturer's instructions. The DNA was then bisulfite-modified using the EZ DNA Methylation kit (Zymo Co., Irvine, CA, USA). Bisulfite treatment converts unmethylated cytosines to uracils while leaving the methylated cytosines unaffected. The modified DNA was amplified using the primers for the methylated and unmethylated sequences of APC and TSLC1 (Table II) (20,21). Each MSP incorporated $100 \mathrm{ng}$ bisulfite-treated DNA as a template, $0.5 \mu \mathrm{mol} / 1$ of each primer, $0.2 \mathrm{mmol} / 1$ deoxynucleoside triphosphate, 10X PCR buffer and 0.75 units of Taq Hot Start Polymerase (Takara Bio, Inc., Shiga, Japan) in a final reaction volume of $25 \mu 1$. The program used for each of the PCR experiments was $95^{\circ} \mathrm{C}$ for $5 \mathrm{~min}$, followed by 35 cycles at $95^{\circ} \mathrm{C}$ for $45 \mathrm{sec}$, annealing temperature for $45 \mathrm{sec}$ (Table II) and $72^{\circ} \mathrm{C}$ for $45 \mathrm{sec}$, followed by an extension at $72^{\circ} \mathrm{C}$ for $7 \mathrm{~min}$. The methylated positive control (in vitro-methylated DNA, IVD) and the unmethylated positive control (DNA from normal human peripheral lymphocytes, NL) were provided by Professor Han Yu (Molecular Biology Institute of China Three Gorges University, Yichang, China). Distilled water was used as a blank control. Amplified products were analyzed on $2.5 \%$ agarose gels.

Western blot analysis. Following treatment, the cells were rinsed with cold PBS and lysed on ice in RIPA buffer (Sigma-Aldrich, St. Louis, MO, USA). Equal amounts of protein from each lysate were loaded onto SDS-PAGE gels and transferred onto a PVDF membrane (Bio-Rad, Hercules, CA, USA). After blocking with 5\% non-fat milk in TBST buffer for $1 \mathrm{~h}$, the membrane was probed with the primary antibodies against DNMT1 (New England Biolabs, Ipswich, MA, USA), APC, TSLC1 and $\beta$-actin (Santa Cruz Biotechnology, Inc., Santa Cruz, CA, USA). Secondary goat anti-rabbit IgG and goat anti-mouse IgG antibodies were purchased from Santa Cruz Biotechnology, Inc. The blotted proteins were visualized using the ECL detection system and X-ray film exposure (Eastman Kodak, Rochester, NY, USA). Protein loading was normalized using anti- $\beta$-actin antibody.

DNMT enzyme activity assay. Nuclear extracts from the TCS-treated and untreated cells were prepared for the DNMT1 enzyme activity assay using the EpiQuik ${ }^{\mathrm{TM}}$ Nuclear Extraction kit (Epigentek Group Inc., Farmingdale, NY, USA). DNMT1 enzyme activity was assayed according to the manufacturer's instructions (EpiQuik ${ }^{\mathrm{TM}}$ Dnmt1 Assay kit; Epigentek Group Inc.). Background levels were determined in incubations without the template DNA. Inhibition was calculated as:

$$
1 \text { - ( }\left(\mathrm{A} 450_{\text {experiment }}-\mathrm{A} 450_{\text {blank }}\right) /\left(\mathrm{A} 450_{\text {control }}-\mathrm{A} 450_{\text {blank }}\right) \times 100 \% .
$$


Table I. Primers used in RT-PCR and q-PCR.

\begin{tabular}{lllcr}
\hline Gene & \multicolumn{1}{c}{ Sequence (5'-3') } & Tm & Product (bp) & Ref. \\
\hline APC & $\begin{array}{l}\text { F: TGTCCCTCCGTTCTTATGGAA } \\
\text { R: TCTTGGAAATGAACCCATAGGAA }\end{array}$ & 51 & 89 & $(17)$ \\
TSLC1 & $\begin{array}{l}\text { F: CCCCAGCCTGTGATGGTAA } \\
\text { R: GGATAGTTGTGGGGGGATCGTA }\end{array}$ & 60 & 196 & $(18)$ \\
DNMT1 & $\begin{array}{l}\text { F: ACCGCTTCTACTTCCTCGAGGCCTA } \\
\text { R: TTGCAGTCCTCTGTGAACACTGTGG }\end{array}$ & 56 & 335 & $(19)$ \\
$\beta$-actin & F: TGGCACCCAGCACAATGAA & & & \\
& R: CTAAGTCATAGTCCGCCTAGAAGCA & 56 & & \\
\hline
\end{tabular}

RT-PCR, reverse transcription-PCR; q-PCR, quantitative real-time PCR; APC, adenomatous polyposis coli; TSLC1, tumor suppressor in lung cancer 1; DNMT1, DNA methyltransferase 1. F, forward; R, reverse; Tm, temperature.

Table II. Primers used in MSP.

\begin{tabular}{llrr}
\hline Gene & \multicolumn{1}{c}{ Sequence (5'-3') } & Tm & Product (bp) \\
\hline APC & $\begin{array}{l}\text { Methylated F: TATTGCGGAGTGCGGGTC } \\
\text { Methylated R: TCGACGAACTCCCGACGA }\end{array}$ & 149 \\
& $\begin{array}{l}\text { Unmethylated F: GTGTTTTATTGTGGAGTGTGGGTT } \\
\text { Unmethylated R: CCAATCAACAAACTCCCAACA }\end{array}$ & 60 & 151 \\
TSLC1 & Methylated F: TAGTATTTTATTAGTTGTTCGTTC & & 109 \\
& Methylated R: GCACACTAAAATCCGCTCG & 58 & $(21)$ \\
& Unmethylated F: TTAGTATTTTATTAGTGTTTGTTT & 56 & $(21)$ \\
& Unmethylated R: CCACACACTAAAATCCACTCA & & 109 \\
\hline
\end{tabular}

MSP, methylation-specific PCR; APC, adenomatous polyposis coli; TSLC1, tumor suppressor in lung cancer 1. F, forward; R, reverse; Tm, temperature.

Statistical analysis. Measurement data were presented as the mean values \pm standard deviation (SD) of experiments conducted in triplicate. Comparisons were evaluated by the Student's t-test. $\mathrm{P}<0.05$ was considered to indicate a statistically significant result. Statistical analyses were performed using the SPSS 13.0 software (SPSS, Inc., Chicago, IL, USA).

\section{Results}

TCS promotes tumor suppressor gene expression. Using RT-PCR, we analyzed the initial mRNA expression levels of the tumor suppressor genes APC and TSLC1 in HeLa and CaSki cells. Following treatment with various concentrations $(0,20,40$ and $80 \mu \mathrm{g} / \mathrm{ml})$ of TCS for $48 \mathrm{~h}$, the expression of the two genes was markedly increased in a dose-dependent manner (Fig. 1A and B). To obtain more detailed expression profiles of the genes, quantitative real-time PCR analysis of the HeLa cells was performed. Following treatment with 20, 40 and $80 \mu \mathrm{g} / \mathrm{ml}$ of TCS, the expression of the APC gene increased 2.55 $\pm 0.29-, 3.44 \pm 0.31-$ and 4.36 \pm 0.14 -fold and that of the TSLC1 gene increased 2.28 $\pm 0.15-, 4.23 \pm 0.88$ - and $6.09 \pm 0.23$-fold, respectively (Fig. 1C and D). Western blot analysis also indicated that the APC and TSLC1 protein levels were increased in a dose-dependent manner following treat- ment with various concentrations of TCS for $48 \mathrm{~h}$ (Fig. 1E). These data indicate that TCS increases tumor suppressor gene expression at the mRNA and protein levels.

TCS induces demethylation in HeLa and CaSki cells. To determine how TCS increases tumor suppressor gene expression, MSP was performed to assess the methylation status of the increased gene and the effect of demethylation by TCS on HeLa and CaSki cells. The results revealed that the methylation status differed between the HeLa and CaSki cells in that APC was completely methylated in HeLa cells but hemimethylated in CaSki cells (Fig. 2A and C). TSLC1 was completely methylated in HeLa and CaSki cells (Fig. 2B and D). Following the treatment of the HeLa and CaSki cells with $40 \mu \mathrm{g} / \mathrm{ml}$ TCS for $48 \mathrm{~h}$, the methylation-specific bands of the genes were decreased and the bands specific for unmethylated genes were enhanced (Fig. 3). These data suggest that TCS induces the demethylation of these tumor suppressor genes.

TCS inhibits DNMT1 enzyme activity and DNMT1 expression. To investigate the mechanism of TCS-induced DNA demethylation, we examined whether the DNMT1 expression level and DNMT1 enzyme activity changed following treatment with TCS. The mRNA expression of DNMT1 was 


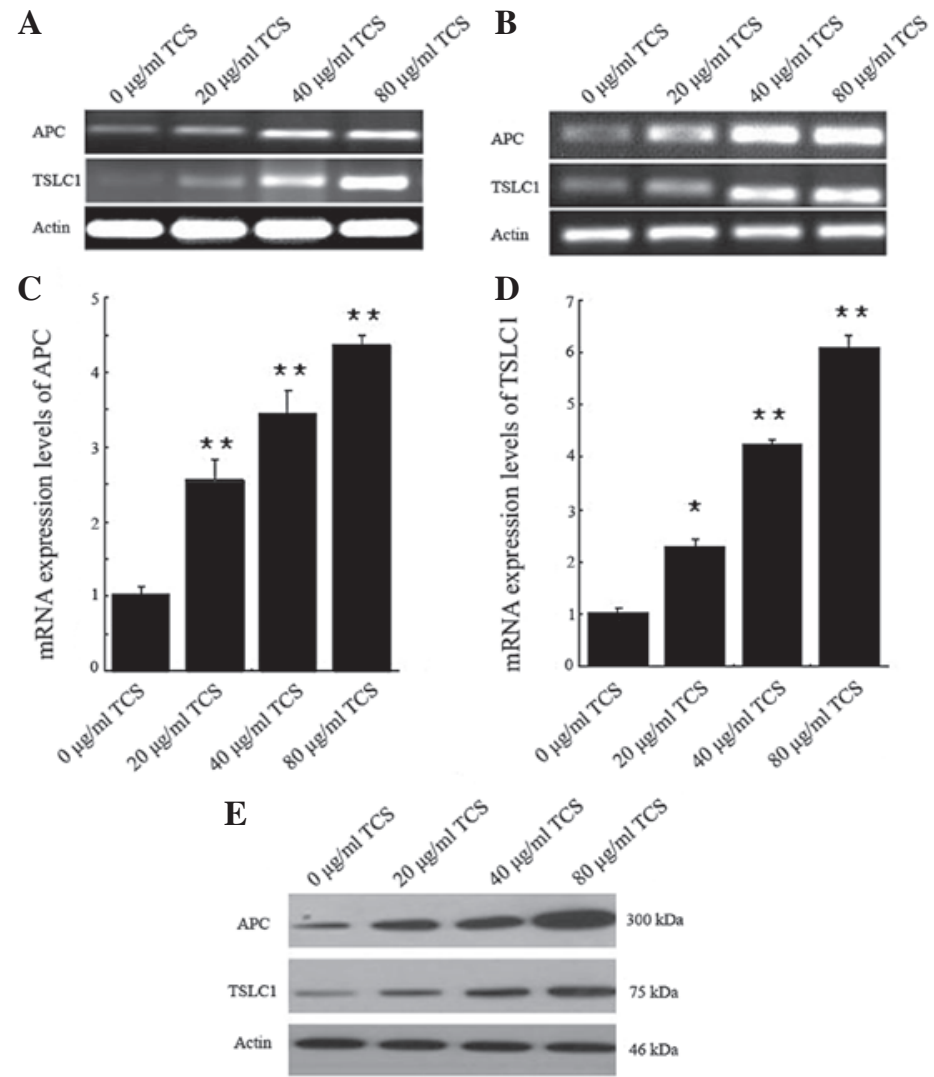

Figure 1. TCS promotes the tumor suppressor gene expression of APC and TSLC1. Alterations of mRNA expression levels of APC and TSLC1 genes following treatment with various concentrations $(0,20,40$ and $80 \mu \mathrm{g} / \mathrm{ml}$ ) of TCS for $48 \mathrm{~h}$ in (A) HeLa cells and (B) CaSki cells are shown. (C and D) Relative mRNA levels of APC and TSLC1 genes following treatment with various concentrations $(0,20,40$ and $80 \mu \mathrm{g} / \mathrm{ml})$ of TCS for $48 \mathrm{~h}$ was determined by quantitative real-time PCR. The values presented are the mean $\pm \mathrm{SD}(\mathrm{n}=3)$ and are statistically significant compared with the control (Student's $\mathrm{t}$-test, ${ }^{*} \mathrm{P}<0.05$, $\left.{ }^{* *} \mathrm{P}<0.01\right)$. (E) Restoration of APC and TSLC1 proteins analyzed by western blot analysis in HeLa cells treated with various concentrations $(0,20,40$ and $80 \mu \mathrm{g} / \mathrm{ml}$ ) of TCS for $48 \mathrm{~h}$. $\beta$-actin expression data were used for protein normalization. APC, adenomatous polyposis coli; TSLC1, tumor suppressor in lung cancer 1; TCS, trichosanthin.
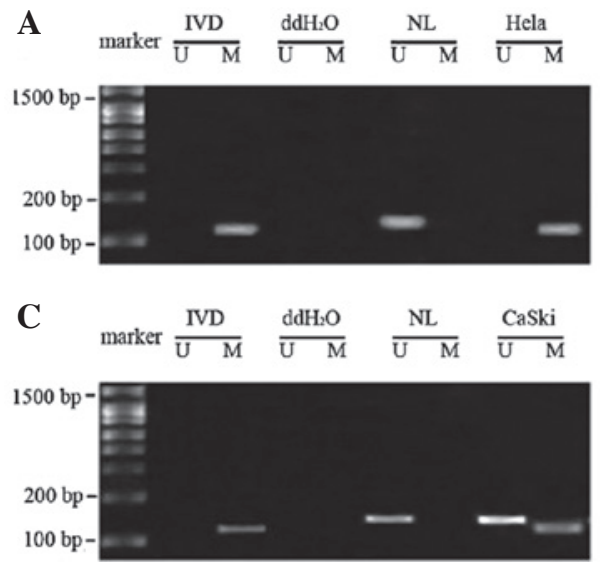
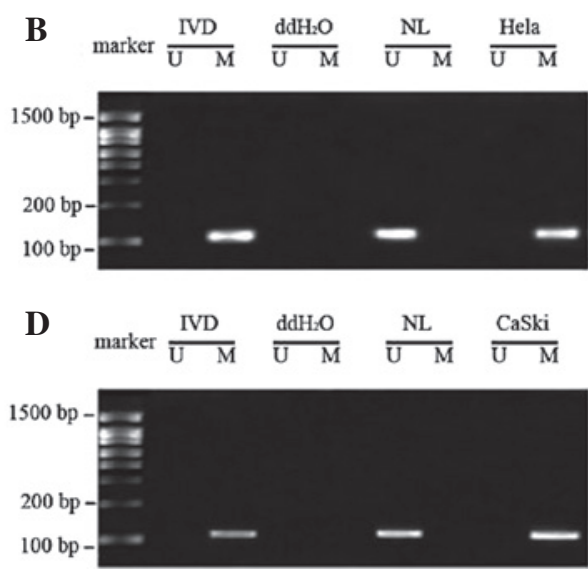

Figure 2. Methylation status of APC and TSLC1 in cervical cancer cells. (A) APC and (B) TSLC1 hypermethylation in HeLa cells. (C) APC hemimethylation in CaSki cells. (D) TSLC1 hypermethylation in CaSki cells. Universal unmethylated/methylated DNA and water blank (no template) were included as controls in each PCR amplification. U, unmethylated; M, methylated; IVD, methylated positive control; NL, unmethylated positive control; dd $\mathrm{H}_{2} \mathrm{O}$, water blank control; APC, adenomatous polyposis coli; TSLC1, tumor suppressor in lung cancer 1.

decreased following treatment with various concentrations $(0$, 20, 40 and $80 \mu \mathrm{g} / \mathrm{ml}$ ) of TCS for $48 \mathrm{~h}$ in cervical cancer cells (Fig. 4A and B). Quantitative real-time PCR assay showed that treatment with 20,40 and $80 \mu \mathrm{g} / \mathrm{ml}$ TCS decreased the expression of DNMT1 $0.76 \pm 0.08-, 0.27 \pm 0.4$ - and $0.19 \pm 0.14$-fold, respectively, in HeLa cells and $0.73 \pm 0.45-, 0.47 \pm 0.6-$ and 0.29 \pm 0.4 -fold, respectively, in CaSki cells (Fig. 4C and D). The protein expression was also decreased following treatment with TCS in a dose-dependent manner (Fig. 5A). DNMT1 enzyme activity was detected in nuclear extracts using 

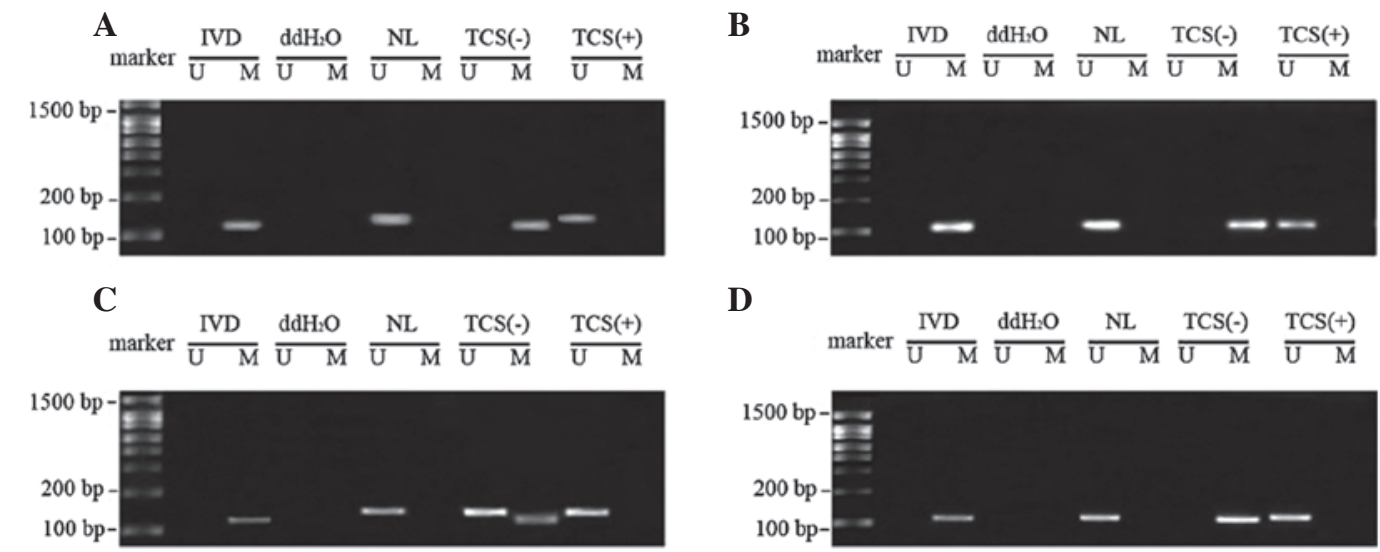

D

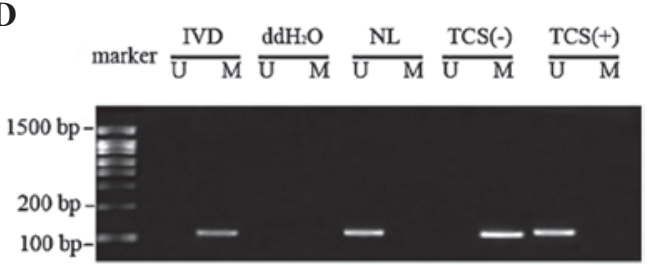

Figure 3. TCS induces demethylation of APC and TSLC1 genes. Alterations of the methylation status of the APC and TSLC1 genes in (A and B) HeLa cells and (C and D) CaSki cells following treatment with $40 \mu \mathrm{g} / \mathrm{ml}$ of TCS for $48 \mathrm{~h}$. U, unmethylated; M, methylated; IVD, methylated positive control; NL, unmethylated positive control; $\mathrm{ddH}_{2} \mathrm{O}$, water blank control; TCS (-), DNA from untreated cells; TCS (+), DNA from cells treated with $40 \mu \mathrm{g} / \mathrm{ml} \mathrm{TCS}$ for $48 \mathrm{~h}$; APC, adenomatous polyposis coli; TSLC1, tumor suppressor in lung cancer 1; TCS, trichosanthin.

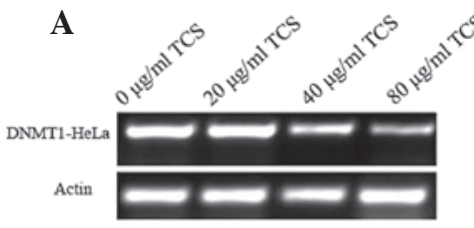

C

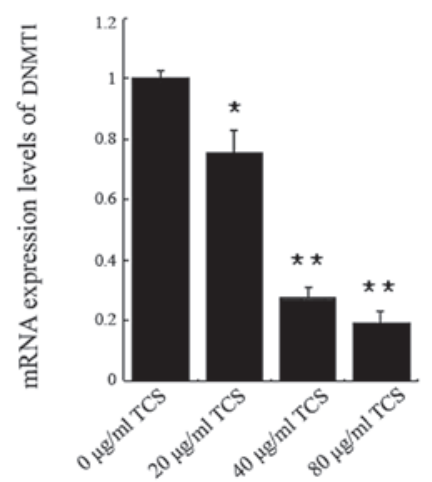

B

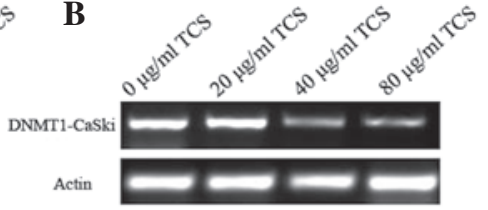

D

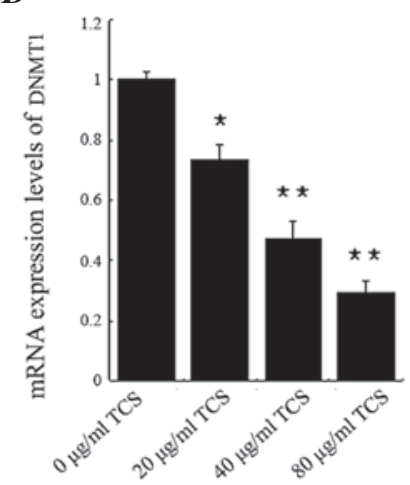

Figure 4. TCS inhibits DNMT1 mRNA expression. (A and B) Alteration of mRNA expression of DNMT1 in HeLa and CaSki cells treated with various concentrations $(0,20,40$ and $80 \mu \mathrm{g} / \mathrm{ml}$ ) of TCS for $48 \mathrm{~h}$. (C and D) Relative mRNA levels of DNMT1 in HeLa and CaSki cells were determined by quantitative real-time PCR. The values presented are the mean $\pm \mathrm{SD}(\mathrm{n}=3)$ and are statistically significant compared with the control (Student's $t$-test, ${ }^{*} \mathrm{P}<0.05$, $\left.{ }^{* *} \mathrm{P}<0.01\right)$. TCS, trichosanthin; DNMT1, DNA methyltransferase 1.

A

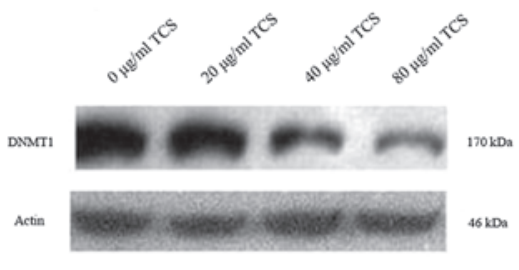

B

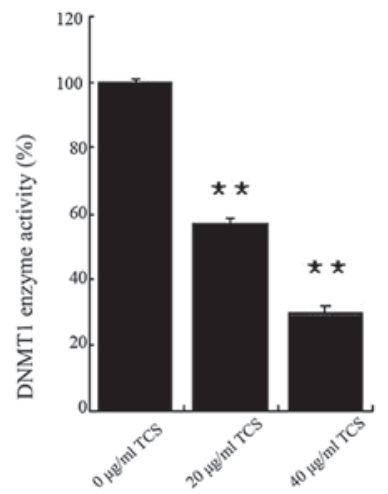

Figure 5. TCS inhibits DNMT1 protein expression and enzyme activity. (A) Decreased expression of DNMT1 protein analyzed by western blotting in HeLa cells treated with various concentrations of TCS for $48 \mathrm{~h}$. $\beta$-actin expression data were used for protein normalization. (B) Inhibition of DNMT1 enzyme activity in HeLa cells treated with various concentrations of TCS for $48 \mathrm{~h}$. The values presented are the mean \pm SD (n=3) and are statistically significant compared with the control (Student's t-test, ${ }^{*} \mathrm{P}<0.05,{ }^{* *} \mathrm{P}<0.01$ ). 
polydeoxyinosine-deoxycytosine as the substrate. Treatment with 20 and $40 \mu \mathrm{g} / \mathrm{ml}$ of TCS for $48 \mathrm{~h}$ inhibited the activity of the DNMT1 enzyme by 31.3 and $56.7 \%$, respectively. The inhibition of DNMT1 by TCS was significant $(\mathrm{P}<0.05)$ in HeLa cells (Fig. 5B).

\section{Discussion}

Cervical cancer is the second most common type of gynecological malignancy worldwide and is the leading cause of cancer mortality in women in developing countries (22). The two major histological types of cervical malignancies are cervical squamous cell carcinoma (CSCC) and cervical adenocarcinoma (CAC) (23). The DNA promoter hypermethylation profiles have been reported to differ between these two histological types of cervical cancer (24). Previous studies have shown that APC promoter hypermethylation is a common feature of CSCC and CAC $(25,26)$. Studies concerning the methylation of TSLC1 are rare as suggested by Steenbergen et al who reported that TSLC1 promoter hypermethylation is the main mode of TSLC1 gene inactivation (18). The present study investigated the methylation status of the tumor suppressor genes APC and TSLC1 in human cervical adenocarcinoma HeLa and human cervical squamous carcinoma CaSki cells. The results showed that the APC gene is completely methylated in HeLa cells and hemimethylated in CaSki cells and that TSLC1 is completely methylated in HeLa and CaSki cells. Our study indicates that promoter hypermethylation resulting in the decreased expression of tumor suppressor genes is a common feature in cervical carcinogenesis. Furthermore, we identified a difference in the methylation status of the tumor suppressor genes between the two cervical cancer cell lines, which is consistent with other studies $(18,25,26)$.

The epigenetic silencing of tumor suppressor genes is a well-established oncogenic process and tumor suppressor gene silencing by promoter methylation is an attractive molecular target for cancer therapy (6). TCS has effective antitumor activities in a variety of tumors and its reported mechanisms of action include the induction of apoptosis and inhibition of cell proliferation (13-15). In the present study, we demonstrated for the first time that TCS induces the demethylation of the $\mathrm{CpG}$ islands of the tumor suppressor genes APC and TSLC1 and restores their expression at the mRNA and protein levels in cervical cancer cell lines. This finding provides a new molecular mechanism for the anticancer effects of TCS.

To investigate the mechanism of TCS-induced DNA demethylation, we examined the effects of TCS on DNMT1 expression and enzymatic activity. Experiments showed that the mRNA and protein expression were decreased following treatment with TCS for $48 \mathrm{~h}$. DNMT1 enzyme activity was also significantly inhibited by TCS. These data show that the demethylation activity was accompanied by a decreased expression of DNMT1 and reduced DNMT1 enzyme activity, suggesting that TCS is a promising demethylating agent. The inhibition of protein synthesis by cleavage of the $\mathrm{N}$-glycosidic bond of a specific adenine of 28S rRNA has been accepted as the mechanism by which plant RIPs cause cytotoxicity (27). Since TCS is a type I RIP, we suggest that TCS downregulation of the DNMT expression and enzyme activity may correlate with this mechanism of RIPs (28). Tumor suppressor gene silencing is mediated by mechanisms other than aberrant methylation in promoter regions, including histone modification (29). Consequently, the use of a single demethylating agent may not be sufficient to achieve the full reversal of epigenetic alterations in native cancer tissues. Studies concerning combination therapies should therefore be performed in cell culture and animal models to validate the efficacy of TCS.

In conclusion, we have demonstrated for the first time that TCS treatment induces the demethylation of the $\mathrm{CpG}$ islands in the promoter regions of the the tumor suppressor genes APC and TSLC1 in cervical cancer cell lines. The rescued expression of these genes was confirmed by quantitative real-time RT-PCR and western blot analysis. Further experimental assays showed that this demethylation activity was accompanied by the decreased expression of DNMT1 and reduced DNMT1 enzyme activity. These data indicate that TCS restores the expression of methylation-silenced tumor suppressor genes and are likely to be useful as a demethylating agent for the treatment of human cancer. These findings also shed a new light on the molecular mechanism for the anticancer effects of TCS.

\section{Acknowledgements}

This study was supported by grants from the Chinese National Natural Science Foundation (No. 30873282), the Foundation of Educational Commission of Hubei Province (B20091303) and the Foundation of the Ministry of Health of Hubei Province (NX2011-9). The authors would like to thank Dr Wenfeng Huang for thoughtful discussions and critical reading of the manuscript, as well as Professor Yu Han for technical assistance.

\section{References}

1. Narayan G and Murty VV: Integrative genomic approaches in cervical cancer: implications for molecular pathogenesis. Future Oncol 6: 1643-1652, 2010.

2. Feng Q, Balasubramanian A, Hawes SE, et al: Detection of hypermethylated genes in women with and without cervical neoplasia. J Natl Cancer Inst 97: 273-282, 2005.

3. Jurkowska RZ, Jurkowski TP and Jeltsch A: Structure and function of mammalian DNA methyltransferases. Chembiochem 12: 206-222, 2011.

4. Turek-Plewa J and Jagodziński PP: The role of mammalian DNA methyltransferases in the regulation of gene expression. Cell Mol Biol Lett 10: 631-647, 2005.

5. Hermann A, Goyal R and Jeltsch A: The Dnmt1 DNA-(cytosineC5)-methyltransferase methylates DNA processively with high preference for hemimethylated target sites. J Biol Chem 279: 48350-48359, 2004.

6. Ren J, Singh BN, Huang Q, et al: DNA hypermethylation as a chemotherapy target. Cell Signal 23: 1082-1093, 2011.

7. Juttermann R, Li E and Jaenisch R: Toxicity of 5-aza-2'-deoxycytidine to mammalian cells is mediated primarily by covalent trapping of DNA methyltransferase rather than DNA demethylation. Proc Natl Acad Sci USA 91: 11797-11801, 1994.

8. Cheng JC, Matsen CB, Gonzales FA, et al: Inhibition of DNA methylation and reactivation of silenced genes by zebularine. J Natl Cancer Inst 95: 399-409, 2003.

9. Dueñas-González A, Lizano M, Candelaria M, et al: Epigenetics of cervical cancer. An overview and therapeutic perspectives. Mol Cancer 4: 38, 2005.

10. Collins EJ, Robertus JD, LoPresti M, et al: Primary amino acid sequence of alpha-trichosanthin and molecular models for abrin A-chain and alpha-trichosanthin. J Biol Chem 265: 8665-8669, 1990.

11. Pan KZ, Lin YJ, Zhou KJ, et al: The crystal and molecular structure of trichosanthin at 2.6 A resolution. Sci China B 36: 1069-1081, 1993. 
12. Li M, Li X and Li JC: Possible mechanisms of trichosanthininduced apoptosis of tumor cells. Anat Rec (Hoboken) 293: 986-992, 2010

13. Ding BN, Chen DJ, Li XR et al: Trichosanthin inhibits growth of breast cancer cells in vitro and in vivo. J Pract Oncol 23: 310-313, 2008.

14. Li J, Xia X, Nie H, et al: PKC inhibition is involved in trichosanthin-induced apoptosis in human chronic myeloid leukemia cell line K562. Biochim Biophys Acta 1770: 63-70, 2007.

15. Li J, Xia X, Ke Y, et al: Trichosanthin induced apoptosis in HL-60 cells via mitochondrial and endoplasmic reticulum stress signaling pathways. Biochim Biophys Acta 1770: 1169-1180, 2007.

16. Zhang CY, An CC, Wang RY, et al: Capillary electrophoresis and circular dichroism study of trichosanthin and its mutants. Talanta 57: 467-473, 2002.

17. Xie L, Wei J, Qian X, et al: CXCR4, a potential predictive marker for docetaxel sensitivity in gastric cancer. Anticancer Res 30 2209-2216, 2010

18. Steenbergen RD, Kramer D, Braakhuis BJ, et al: TSLC1 gene silencing in cervical cancer cell lines and cervical neoplasia. J Natl Cancer Inst 96: 294-305, 2004.

19. Minami K, Chano T, Kawakami T, et al: DNMT3L is a novel marker and is essential for the growth of human embryonal carcinoma. Clin Cancer Res 16: 2751-2759, 2010.

20. Arnold CN, Goel A, Niedzwiecki D, et al: APC promoter hypermethylation contributes to the loss of APC expression in colorectal cancers with allelic loss on 5q. Cancer Biol Ther 3 : 960-964, 2004.
21. Murray PG, Fan Y, Davies G, et al: Epigenetic silencing of a proapoptotic cell adhesion molecule, the immunoglobulin superfamily member IGSF4, by promoter $\mathrm{CpG}$ methylation protects Hodgkin lymphoma cells from apoptosis. Am J Pathol 177: 1480-1490, 2010.

22. Jemal A, Siegel R, Ward E, et al: Cancer statistics. CA Cancer J Clin 59: 225-249, 2009.

23. Sasieni $\mathrm{P}$ and Adams J: Changing rates of adenocarcinoma and adenosquamous carcinoma of the cervix in England. Lancet 357: 1490-1493, 2001.

24. Kang S, Kim JW, Kang GH, et al: Comparison of DNA hypermethylation patterns in different types of uterine cancer: cervical squamous cell carcinoma, cervical adenocarcinoma and endometrial adenocarcinoma. Int J Cancer 118: 2168-2171, 2006.

25. Ying Y and Tao Q: Epigenetic disruption of the WNT/betacatenin signaling pathway in human cancers. Epigenetics 4: 307-312, 2009

26. Wentzensen N, Sherman ME, Schiffman M and Wang SS: Utility of methylation markers in cervical cancer early detection: appraisal of the state-of-the-science. Gynecol Oncol 112: 293-299, 2009.

27. Wu S, Lu XH, Zhu YR, et al: N-glycosidase mechanism of Trichosanthin. Sci China C Life Sci 41: 174-180, 1998.

28. Nie H, Cai X, He X, et al: Position 120-123, a potential active site of trichosanthin. Life Sci 62: 491-500, 1998.

29. Huang J, Plass C and Gerhauser C: Cancer chemoprevention by targeting the epigenome. Curr Drug Targets 12: 1925-1956, 2011. 